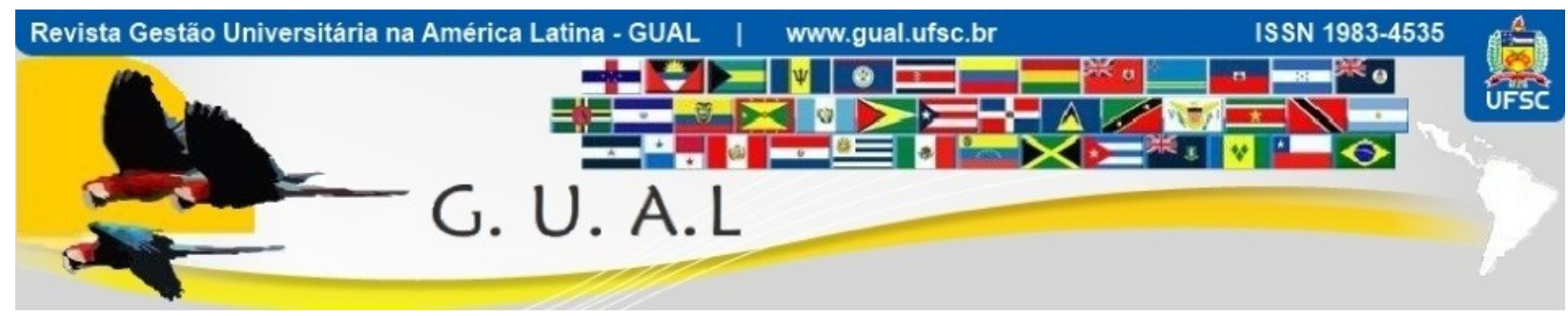

DOI: http://dx.doi.org/10.5007/1983-4535.2013v6n1p156

\title{
O ENSINO DE ADMINISTRAÇÃO DA UNIJUII: QUATRO DÉCADAS DE HISTÓRIA
}

\section{THE EDUCATION OF ADMINISTRATION OF UNIJUÍ: FOUR DECADES OF HISTORY}

\author{
Enise Barth Teixeira, Doutora \\ Universidade Regional do Noroeste do Estado do Rio Grande do Sul - Unijuí \\ enise@unijui.edu.br \\ Alexandre Dal Molin Wissmann, Graduando \\ Universidade Regional do Noroeste do Estado do Rio Grande do Sul - Unijuí \\ alewissmann@hotmail.com
}

Recebido em 13/agosto/2012

Aprovado em 12/dezembro/2012

Sistema de Avaliação: Double Blind Review

Esta obra está sob uma Licença Creative Commons Atribuição-Uso. 


\begin{abstract}
RESUMO
O artigo objetiva resgatar e descrever a história dos quarenta anos do curso de Administração da Unijuí, situado na cidade de Ijuí/RS. O desenvolvimento deste estudo baseia-se na análise de documentos históricos e nas percepções dos três professores precursores, explorando as memórias, sobretudo os aspectos mais marcantes ao longo dessa trajetória. A pesquisa classifica-se como exploratória qualitativa. O estudo de caso constitui-se na estratégia de investigação. Os procedimentos técnicos empregados foram pesquisa bibliográfica, documental e de campo. A entrevista semi-estruturada foi a técnica utilizada para a coleta dos dados empíricos. Os resultados do estudo evidenciam os desafios e as dificuldades enfrentados, assim como fatos relevantes vivenciados ao longo das quatro décadas de ensino de Administração na Unijuí. A retomada da história do curso de Administração sob a ótica dos docentes pioneiros e de documentos históricos reveste-se de significativa importância no tocante à memória desta graduação na linha do tempo, assegurando deste modo a armazenagem de informações e seus significados. A história, além de recuperar o passado, permite melhor compreensão do presente, e assim projetar o futuro do ensino da Administração e sua contribuição no desenvolvimento regional sustentável.
\end{abstract}

Palavras-chave: História. Memória. Curso de Administração. Percepção. Professores.

\begin{abstract}
The present article aims rescue and describe the history of forty years of the Administration course at Unijuí, situated at the city of Ijuí/RS. The development of this study is based in the analysis of historical documents and perceptions of three pioneers professors, exploring the memories, mainly the most striking aspects along this path. The research ranks as qualitativeexplorative. The study of case constitutes on the strategy of investigation. The technical procedures used were bibliographical, documental and empirical research. The semistructured interview was the utilized technique for the empirical data collect. The study results show the challenges and difficulties faced, as well as relevant facts lived along the four decades of Administration education of Unijuí. The resumed history of the Administration course viewed by the pioneer docents and historic documents are lined of great importance on the memory of this graduation during its timeline, ensuring thus the information storage and its meanings. The history, beyond the past recover, allows a better comprehension of present and so can design the future of the Administration education and its contribution on the sustainable regional development.
\end{abstract}

Keywords: History. Memory. Administration course. Perception. Professors. 


\section{INTRODUÇÃO}

Atualmente são desenvolvidas pesquisas voltadas para a memória das instituições, sua trajetória ao longo do tempo como forma de resgatar seu passado, permitindo melhor compreensão do presente e também auxiliando na projeção futura, como trabalhos de (BARBOSA; OTT, 2009) e (BORENSTEIN; ALTHOFF; SOUZA, 1999) que retratam esse contexto. Este conhecimento sistematizado, na visão de Saraiva e Costa (2010) contribui para a identidade sócio-cultural das organizações.

A pesquisa sobre a historiografia das instituições se caracteriza conforme Vergara (2005) por analisar documentos, relatos orais e também a iconografia da empresa. Uma forma de resgatar esses fatos históricos é conversando com os sujeitos que fizeram parte desta trajetória, como ressalta Fischer (2010). A referida autora estabelece quatro níveis de pesquisa para estudar a trajetória das instituições de ensino, e o primeiro deles é justamente pesquisar a vida dos professores que idealizaram a partir de seus trabalhos as metodologias, os campos de ensino e a organização do curso.

Neste contexto, torna-se oportuno desenvolver uma pesquisa sobre a historiografia do Curso de Administração da Unijuí que em agosto de 2011, completou 40 anos de atuação.

O presente estudo tem como propósito trazer à tona a história do curso a partir de seus docentes fundadores resgatando aspectos históricos, além de evidenciar fatos, como os principais desafios na sua constituição, as expectativas, a capacitação dos docentes e também abordar quais as principais contribuições que o curso trouxe para o desenvolvimento da região.

O texto se divide em seis partes, sendo a primeira é a introdução, na qual se apresenta o tema central e explicita o objetivo. A segunda apresenta o quadro teórico de referência, que aborda a gestão do conhecimento e a memória organizacional, a histografia e a história do ensino da Administração no Brasil e RS. Os aspectos metodológicos são apresentados na terceira parte. O curso de Administração da Unijuí e suas particularidades compreendem a quarta parte deste artigo. A história do curso na percepção dos docentes precursores do curso é descrita na parte subsequente. A sexta e última parte trata das considerações finais do estudo.

\section{QUADRO TEÓRICO DE REFERÊNCIA}

Os fundamentos teóricos que sustentam a pesquisa em tela compõem-se de três 
tópicos. O primeiro versa sobre a Gestão do Conhecimento e a Memória Organizacional, na sequência apresenta-se uma abordagem sobre a Historiografia das Organizações, e por fim é contextualizada a História do Ensino da Administração no Brasil e no Rio Grande do Sul.

\subsection{GESTÃO DO CONHECIMENTO E MEMÓRIA ORGANIZACIONAL}

O conhecimento e a aprendizagem, no atual contexto, constituem-se em recursos estratégicos de primeira grandeza. O conhecimento organizacional é fruto das interações que ocorrem no referido ambiente e que são desenvolvidos por intermédio do processo de aprendizagem. O conhecimento para Fleury e Oliveira Jr (2001) também pode ser entendido como informações associadas à experiência, à intuição e aos valores.

$\mathrm{Na}$ visão de Nonaka e Takeuchi (1997) podem ser distinguidos dois tipos de conhecimento: conhecimento tácito e conhecimento explícito. O conhecimento explícito, ou codificado, refere-se ao conhecimento transmissível em linguagem formal, sistemática; já o conhecimento tácito possui uma qualidade pessoal, o que torna sua formalização e comunicação mais difíceis. "O conhecimento tácito é profundamente arraigado na ação e no comprometimento e no envolvimento do indivíduo com determinado contexto" (NONAKA, 2000, p. 33).

O conhecimento é um ativo corporativo fluido, importante, e que necessita de gerenciamento (SPENDER, 2001). O processo de gestão do conhecimento numa organização se dá em três momentos: aquisição e desenvolvimento de conhecimentos, disseminação e construção de memória (FLEURY, 2001).

A construção da memória organizacional refere-se ao processo de armazenagem de informações com base na história da empresa, que podem ser recuperadas e, assim, auxiliar a tomada de decisões no momento presente (FLEURY, 2001, p. 94).

Nesta mesma linha de pensamento, Saraiva e Costa (2010) afirmam que a memória organizacional tem dois objetivos, manter a coesão interna e de manter as fronteiras daquilo que se tem em comum, isto faz com que estas pessoas se sintam um grupo, e as diferencia das demais, mostrando o quanto isto é importante dentro das empresas.

\subsection{HISTORIOGRAFIA}

A pesquisa sobre o ensino nas diversas áreas já tem uma longa caminhada. A partir desta base Wainandt, Fischer e Fonseca (2010) destacam que a pesquisa começou a se projetar a partir de 1930 na Escola de Annales, quando esta ampliou o campo de pesquisas 
que antes era baseado em acontecimentos da empresa de uma forma mais positiva. Porém só em 1984 que as pesquisas neste sentido ganharam mais força no Brasil, principalmente com a criação do Grupo de Trabalho (GT) pela Associação Nacional de Pesquisa e Pós-Graduação em Educação (ANPED), dando um grande impulso na produção da pesquisa sobre a historiografia das organizações.

Curado (2001, p. 5) afirma que "algumas empresas estão buscando consultoria especializada para catalogação de documentos e recuperação de sua história, via coleta de depoimentos. Isso ocorre em função de uma valorização da história e, em alguns casos, da necessidade de resgatar o desenvolvimento da empresa”. Reflexo disso é que as organizações estão reconhecendo a importância de considerar sua história, e algumas inclusive organizam suas memórias em livros, principalmente as que são mais longevas.

Ao conhecer melhor o passado da instituição, a sua história, poder-se-á identificar melhor seus pontos fracos e, principalmente, suas potencialidades (ANDRADE; AMBONI, 2002).

Corroborando com os autores, Fischer (2010) apresenta quatro formas de pesquisa sobre a historiografia das instituições de ensino superior, além da história contada pelos professores que arquitetaram o curso, são formas de explicitar também esta memória a história dos currículos; seu modo de ensinar e aprender; a história da disciplina ou a história da evolução do pensamento na área e, por fim, a história das instituições no Brasil.

Tendo em vista que a historiografia é um campo muito amplo, Marques (2008) explica que os pesquisadores que têm a oportunidade de trabalhar em pesquisas e estudos com empresas que ainda estão em funcionamento, o uso da história oral ganha fundamental valor não só pela oportunidade de preencher as lacunas existentes, como também oferecer um canal para a reconstrução da cultura organizacional.

\subsection{O ENSINO DE ADMINISTRAÇÃO NO BRASIL E NO RIO GRANDE DO SUL}

No Brasil, a história do ensino da Administração começou a se configurar no ano de 1938, quando a Fundação Getúlio Vargas (FGV) criou o Departamento de Administração do Serviço Público (DASP), tendo como principal objetivo era aumentar a qualidade da Administração pública federal e capacitar o recrutamento dos novos funcionários. No ano de 1941, em São Paulo foi criado o primeiro curso de Administração do Brasil e da América Latina na Escola Superior de Administração de Negócios (ESAN), como menciona Fischer (2010). . 
Foi nesta década que o papel do administrador ganhou mais força, pois se aumentava a necessidade de mão de obra qualificada no mercado de trabalho. Um fato que pode ilustrar isso de forma mais concreta foi o primeiro Congresso Brasileiro de Economia em 1943 no Rio de Janeiro, neste foi identificado o grande interesse pela industrialização do país, assim o estado precisava mostrar iniciativas para motivar a pesquisa na área econômica nacional.

Complementando a ideia Andrade e Amboni (2002) destacam que foi em consequência disto que em 1945, Gustavo Capanema, ministro da Educação na época enviou um documento para a presidência que sugeria a criação de dois cursos: Ciências Contábeis e Ciências Econômicas (antes disto só existiam Medicina, Engenharia e Direito), tal sugestão foi dada pelo fato de que as empresas precisavam de técnicos possuindo um maior nível de entendimento nestas áreas, devido à complexidade atingida, e por esse motivo o pedido foi aceito.

Cabe ressaltar que o ensino da Administração no País está muito ligado ao desenvolvimento econômico, que teve dois momentos marcantes: o primeiro no governo de Getúlio Vargas, com seu projeto autônomo, de caráter nacionalista. E o segundo, no governo de Juscelino Kubitschek, pelo projeto de abertura econômica de caráter internacionalista, como afirma Coimbra (2010).

Na década de 50, a FGV criou a Escola Brasileira de Administração Pública (EBAP) no Rio de Janeiro e logo depois a Escola de Administração de Empresas de São Paulo (EAESP), esta foi criada na cidade de São Paulo, justamente por ser o maior polo econômico do país.

Outra instituição que foi e ainda é referência na área, é a Faculdade de Economia e Administração (FEA), da Universidade de São Paulo, ela também foi uma das pioneiras no ensino no Brasil, porém foi somente no início dos anos 60, que a FEA, que antes era composta pelos cursos de Ciências Econômicas e Contábeis, deu origem ao Departamento de Administração. No entanto foi só no ano de 1963 que o curso de graduação em Administração de Empresas e Administração Pública foi criado.

A regulamentação da atividade pela Lei no 4.769 de nove de setembro de 1965, foi um fato muito importante para a profissão, o que abriu um grande campo para os administradores de empresas ou setores públicos.

Um dado interessante que demonstra a evolução dos cursos em Administração ao passar do tempo, é que antes da década de 60, só existiam dois cursos de nível superior em Administração, e alguns anos mais tarde, já na década de 1990 eram 823 cursos. 
No Estado do Rio Grande do Sul a precursora do curso de Administração, criado em 15 de março de 1931, e reconhecido em 1968 foi a Pontifícia Universidade Católica do Rio Grande do Sul, mais tarde vieram UFRGS, a UNISINOS e a UFSM. Atualmente o estado possui 88 cursos superiores em Administração, conforme dados do MEC.

\section{METODOLOGIA DA PESQUISA}

A presente pesquisa classifica-se como um estudo qualitativo, do tipo exploratóriodescritivo (MINAYO, 1994). A estratégia de pesquisa adotada é o estudo de caso único (YIN, 2001).

No processo de coleta dos dados foram empregadas duas fontes: as entrevistas com as pessoas que vivenciaram o fenômeno em análise e os documentos, como sugerem Saraiva e Costa (2010) para a realização de pesquisas voltadas a memória organizacional.

No desenvolvimento de estudos histográficos, Vergara (2005) sugere o emprego de fontes primárias e secundárias. As técnicas mais indicadas para o levantamento dos dados empíricos são entrevistas, diários, cartas pessoais, já para os dados secundários são recomendados os estudos publicados sobre o tema, filmes ou entrevistas com estudiosos. Por fim, é importante fazer a comparação entre as fontes escritas, documentos manuscritos ou impressos com as não escritas, como filmes, fotografias e entrevistas.

A primeira parte da pesquisa foi voltada para a pesquisa exploratória qualitativa, com a análise de documentos históricos e, também, atuais. Esta etapa foi desenvolvida de forma satisfatória, uma vez a Fundação Mantenedora da Universidade conta com o Museu Antropológico Diretor Pestana (MADP), que preserva documentos textuais/bibliográficos e iconográficos de significativo valor histórico e cultural. Foram pesquisados relatórios e balanços anuais, que registram os fatos mais relevantes do curso, as mudanças nos quadros funcionais, os trabalhos publicados, as atividades realizadas no período, entre outras informações. Merece destacar que neste acervo encontram-se tanto fotos como documentos referentes ao pedido de funcionamento do Curso e a solicitação de reconhecimento.

A segunda parte da investigação foram às pesquisas de campo, aos monumentos da instituição, neste caso as entrevistas com os sujeitos da pesquisa, os professores que fundaram o curso, com a possibilidade de fácil acesso a estes por estarem residindo ainda na cidade e manterem relação com a Universidade.

A entrevista é "uma interação verbal, uma conversa, um diálogo, uma troca de significados, um recurso para se produzir conhecimento sobre algo", como afirma Vergara 
(2009, p. 03). A entrevista realizada é do tipo semi-estruturada, com um roteiro de perguntas previamente elaborado. As questões indagaram cinco aspectos: o que representou o curso de Administração no projeto da Fundação de Integração, Desenvolvimento e Educação do Noroeste do Estado (FIDENE), o no contexto do desenvolvimento local e regional; quais foram os principais desafios na criação e implantação do curso; as expectativas dos docentes; de que forma os professores buscaram se capacitar tanto nos aspectos teóricos como nas questões práticas e quais foram os fatos mais marcantes.

Os três professores fundadores do curso que foram entrevistados são:

\begin{tabular}{|c|c|}
\hline Professor(a) & Formação \\
\hline Neyta Oliveira Belatto & $\begin{array}{c}\text { Graduação em Sociologia, Especialista em Planejamento Urbano e } \\
\text { Mestrado em Administração Pública }\end{array}$ \\
\hline Antônio José Grison & $\begin{array}{c}\text { Graduação em Filosofia e em Pedagogia, Mestrado em Administração } \\
\text { Pública }\end{array}$ \\
\hline Paulo Afonso Frizzo & $\begin{array}{c}\text { Graduação em Filosofia e Pedagogia e Especialista em Administração } \\
\text { Pública }\end{array}$ \\
\hline
\end{tabular}

Quadro 1 Professores entrevistados Fonte: Dados da Pesquisa

Os professores Grison e Neyta já se encontram aposentados, contudo costumam interagir com os professores do Curso de Administração, e o professor Frizzo, ainda integra o corpo docente do Curso.

As entrevistas foram agendadas com os professores, marcando-as em local mais conveniente para os mesmos, sendo que uma ocorreu numa residência e duas em ambiente de trabalho. Em termos de tempo as entrevistas tiveram uma duração em torno de uma hora. Vale destacar que, os docentes demonstraram entusiasmo em abordar as questões levantadas, confirmando sentimentos de realização pessoal pelo projeto profissional e institucional. A apresentação dos dados de identificação, dos depoimentos dos professores pesquisados, decorre do consentimento dos mesmos.

A análise dos dados das entrevistas e das informações retiradas nos documentos históricos no MADP permitiu uma visão mais ampla das situações ao longo destas quatro décadas, mostrando uma maior riqueza nos detalhes com o cruzamento destas duas fontes.

\section{O CURSO DE ADMINISTRAÇÃO DA UNIJUÍ}

\subsection{ANTECEDENTES DO CURSO DE ADMINISTRAÇÃO}

A história do curso de Administração em Ijuí começa a ser desenhada muito antes de 1971, data de sua criação, ela começa mais precisamente em 1953, quando se fundou o Centro 
de Estudos Pedagógicos “Antônio Balbino”, de Ijuí, unificando os Educadores da cidade, para Intercâmbio e promoções culturais.

Em conjunto com o Centro Pedagógico, os Frades Menores Capuchinhos, presentes em Ijuí desde 1949, concretizaram uma ideia que vinha de anos, de instrumentalizar os jovens da região com um curso superior. Então em 1956 surgiu a FAFI (Faculdade de Filosofia, Ciências e Artes), um marco muito importante para a cidade e para a região, que teve no ano seguinte seu reconhecimento pelo Decreto $n^{\circ}$ 40.936, de 14 de fevereiro de 1957.

No dia 16 de março de 1957 foi realizada no salão de festas da Sociedade Ginástica de Ijuí a solene instalação da Faculdade de Filosofia, Ciências e Letras de Ijuí. E para esta data importante para a Faculdade o Reitor da Pontifícia Universidade Católica do Rio Grande do Sul, Ir. José Otão pronunciou a aula inaugural, abordando o tema "Saber e Cultura".

Todo trabalho realizado pela FAFI veio amadurecendo a ideia de uma Fundação para o desenvolvimento da região noroeste do Estado, pelo planejamento e pela instrumentalização, através de órgãos e serviços que se revelassem necessários. Lançado isto, aos poucos a região foi respondendo com adesões e trabalho conjugado.

Desta forma, várias reuniões começaram a ser feitas por delegações de diversos municípios da região noroeste, e alguns anos depois, em 1969 é criada a FIDENE - Fundação de Integração, Desenvolvimento e Educação do Noroeste do Estado do Rio Grande do Sul, que tinha como um de seus objetivos criar mais áreas de atuação da Faculdade. Um ano depois, foi concebida a FACACEI - Faculdade de Ciências Administrativas, Contábeis e Econômicas de Ijuí. E em 1971 o curso de Administração foi criado, contudo só em 1974 foi reconhecido pelo Conselho Federal de Educação.

A Figura 2 demonstra os principais fatos na criação da FACACEI, e na criação do Curso de Administração em 1971. No dia 7 de agosto de 1971, portanto foi inaugurada a FACACEI, com a primeira aula do Curso de Administração. O compromisso com a realidade regional, que sempre norteou os caminhos da FIDENE, foi decisivo ao longo dos anos para uma trajetória de desenvolvimento e integração, objetivos desta instituição, que passou por muitos processos, buscando permanentemente consolidar com qualidade sua atuação no Ensino Superior.

\begin{tabular}{|c|c|}
\hline Data & Fato Marcante \\
\hline 30 de Janeiro de 1970 & $\begin{array}{r}\text { Celebração do convênio com a Fundação Getúlio Vargas, do Rio de Janeiro, para } \\
\text { aperfeiçoamento do corpo docente, da FIDENE, no curso de Mestrado realizado pela } \\
\text { Escola Brasileira de Administração Pública. }\end{array}$ \\
\hline
\end{tabular}




\begin{tabular}{|c|c|}
\hline 12 de Junho de 1970 & $\begin{array}{r}\text { Criação da Faculdade de Ciências Administrativas, Contábeis e Econômicas de Ijuí } \\
\text { pelo Conselho Diretor da FIDENE. }\end{array}$ \\
\hline $\begin{array}{c}8 \text { de Dezembro de } \\
1970\end{array}$ & $\begin{array}{r}\text { Celebração de convênio com a Escola de Administração de Empresas de São Paulo, } \\
\text { da Fundação Getúlio Vargas, para aperfeiçoamento de professores da FIDENE em } \\
\text { cursos de Pós Graduação daquela escola. }\end{array}$ \\
\hline 31 de março de 1971 & $\begin{array}{r}\text { Aprovação pelo Conselho Federal de Educação do Parecer 213/71, relatado pelo } \\
\text { Conselheiro José Fonseca Milano, favorável à autorização para o funcionamento da } \\
\text { Faculdade de Ciências Administrativas, Contábeis e Econômicas de Ijuí. }\end{array}$ \\
\hline 7 de agosto de 1971 julho de 1971 & $\begin{array}{r}\text { Decreto federal no 68.978, que autoriza o funcionamento da Faculdade de Ciências } \\
\text { Administrativas, Contábeis e Econômicas de Ijuí. }\end{array}$ \\
\hline $\begin{array}{r}\text { Solenidade de instalação oficial da Faculdade de Ciências Administrativas, Contábeis } \\
\text { e Econômicas de Ijuí, pronunciando a aula magna o Dr. Dolmy Tarrasconi, Secretário } \\
\text { da Administração do Governo do Estado do RS. }\end{array}$ \\
\hline
\end{tabular}

Quadro 2 Fatos Marcantes da Criação do Curso de Administração

Fonte: FIDENE. Relatório Trianual de 1969 a 1971, p. 17-18.

Dentre os fatos marcantes desta instituição, destaca-se a obtenção do reconhecimento como Universidade, em 28 de junho de 1985, quando passa a ser chamada UNIJUÍ, e é batizada por Tancredo Neves como a "primeira universidade da Nova República”. E, em consequência disto, não só o curso de Administração, como todos os demais passaram a ter um novo posicionamento e credibilidade por toda a região Noroeste do Estado do RS.

\subsection{A CRIAÇÃO DO CURSO DE ADMINISTRAÇÃO}

À medida que foi se concretizando a ideia de um órgão de Integração e Desenvolvimento regional, que acabou resultando na criação da FIDENE, a convicção da necessidade para a região de um Curso de Administração também foi tomando forma. Com a finalidade de preparar os recursos humanos indispensáveis e, sobretudo de fixar técnicos que pudessem aliar, na qualidade de professores de ensino superior, as preocupações de ordem prática e executiva às lides do ensino e da pesquisa, condição indispensável para o aperfeiçoamento contínuo e o acompanhamento obrigatório das conquistas da ciência e da técnica.

Institucionalizada a FIDENE, uma das primeiras preocupações da direção superior foi a de atrair para seus quadros executivos, pessoal técnico de formação especializada e preparar a criação do Curso de Administração, com a primeira medida a ser tomada, a constituição de seu corpo docente.

Dentre as primeiras ações, merece ressaltar a celebração de um convênio com a Fundação Getúlio Vargas, para vagas anuais no Curso de Mestrado da Escola Brasileira de Administração Pública destinadas a bolsistas da FIDENE. Tão logo assinado o acordo, os três 
Professores Antônio José Grison, Neyta Oliveira e Paulo Afonso Frizzo já se encontravam no

Rio de Janeiro para o Curso de Mestrado.

Com os docentes qualificados para o exercício do magistério no Curso de Administração, em sete de agosto de 1971 ocorreu a primeira aula.

Em relação ao novo curso em instalação, o Professor Argemiro Jacob Brum mencionou que:

A nova Faculdade e o novo Curso abrem mais amplas perspectivas para a vida educacional e cultural, assim como para a habilitação profissional, em Ijuí e na região. A conquista é um passo significativo para a nossa instrumentalização para o desenvolvimento e afirmação da liderança cultural. Uma 'idéia' torna-se realidade e se traduz em resposta positiva às necessidades do desenvolvimento (FIDENE, 1972, p. 17).

O Curso de Administração foi concebido para atingir os seguintes propósitos de acordo com o pedido de funcionamento:

prover a formação, especialização e o aperfeiçoamento de pessoal para empreendimentos públicos e privados; colaborar no planejamento global e setorial e na motivação para a organização de serviços ou empreendimentos e prestar-lhes a assistência técnica necessária; assessorar os governos municipais, as atividades sócio-culturais e as organizações empresariais no planejamento e execução de projetos específicos. [...]

Com tal objetivo a FIDENE tratou logo de fixar na região, dando-lhes condições de trabalho e de aperfeiçoamento, técnicos e especialistas na área da Administração, o que importa em, além de lhes criar mercado de trabalho, proporcionar-lhes, pelo exercício do magistério superior, condições de aperfeiçoamento contínuo e acompanhamento obrigatório das conquistas da ciência e da técnica no mundo de hoje, aliando às preocupações de ordem prática e executiva as lidas do ensino e da pesquisa. A fixação de pessoal de alto nível e a dinamização constante de sua presença e atuação só será possível através da institucionalização dessa presença e atuação em uma escola de nível superior, brotada assim das necessidades da região e convertida em centro dinamizador, capaz de prover, na região e para a região, a formação do pessoal necessário em nível, ao menos de execução. Pouco mais de um ano de existência da FIDENE nos mostram que com uma ação com a que pretende ela desenvolver na região exige sempre mais pessoal habilitado, criando assim e expandindo o mercado de trabalho técnico e especializado. Uma equipe de técnicos trazida a região, se de início parecia empresa arriscada por não se lhes poder dar pleno emprego, revelam-se, apenas alguns meses depois, insuficiente, incapaz de dar atendimento pleno à demanda que em tão breve prazo se criara. Pretende-se até inícios de 1971 ter aqui uma equipe de cerca de 20 técnicos preparados em nível de Pós-Graduação, equipe que exigirá a complementação de pessoal graduado. A FIDENE já procura instrumentalizar seus quadros através de cursos rápidos ministrados a professores, estudantes universitários e técnicos de nível médio. Está mesmo por celebrar convênio com a SUDESUL, já aprovado nos escalões superiores, para um Curso de Treinamento em Planejamento Local Integrado, para profissionais de nível superior. Tais exigências, porém, somente poderão ser integralmente satisfeitas através de um curso de graduação que habilite, dentro das exigências legais, ao exercício da profissão. Tais são os objetivos que pretende a FIDENE atingir através do Curso de Graduação em Administração, para que solicita autorização de funcionamento. (FIDENE, 1970, p. 621). 
A preocupação da qualificação docente para o Curso sempre foi uma constante entre os princípios da direção da Faculdade. Para isso, desde o início foram firmados convênios para que o exercício do magistério fosse conduzido de maneira que respondesse as expectativas dos alunos. Além do convênio celebrado com a FGV do Rio de Janeiro já citado anteriormente, outros foram firmados no início do Curso, como expressa a Quadro 3.

\begin{tabular}{|c|c|}
\hline Instituição & Finalidade \\
\hline $\begin{array}{c}\text { Fundação Getúlio Vargas (SP) - Escola de } \\
\text { Administração de Empresas }\end{array}$ & Formar professores para a FACACEI \\
\hline $\begin{array}{c}\text { Instituto Brasileiro de Administração Municipal - } \\
\text { IBAM }\end{array}$ & $\begin{array}{c}\text { Treinamento de técnicos e professores em Administração } \\
\text { Municipal e Planejamento Local Integrado }\end{array}$ \\
\hline $\begin{array}{c}\text { Faculdade de Ciências Econômicas, da UFRGS } \\
\text { (RS) - Instituto de Administração (IA) }\end{array}$ & $\begin{array}{c}\text { Envio de professores ao Curso de Pós-Graduação em } \\
\text { Administração }\end{array}$ \\
\hline $\begin{array}{c}\text { Programa Ecumênico de Bolsas de Estudo } \\
\text { (Alemanha) }\end{array}$ & $\begin{array}{c}\text { Bolsas de estudo para habilitação e especialização de } \\
\text { professores em nível de Pós-Graduação }\end{array}$ \\
\hline $\begin{array}{c}\text { Fundação FORD } \\
\text { Patrocínio de pesquisas da FIDENE referentes a } \\
\text { Educação }\end{array}$ \\
\hline
\end{tabular}

Quadro 3 Convênios firmados com a FIDENE

Fonte: FIDENE. Relatório Trianual de 1972 a 1974. p. 29-31

A busca em manter relações institucionais com outras entidades foi um dos alicerces para a FIDENE concretizar seu projeto de ensino superior com credibilidade, dando a sua equipe de trabalho a possibilidade de aperfeiçoamento, configurando num aspecto de grande relevância para a consolidação do curso na região.

\subsection{CONSOLIDAÇÃO DO ENSINO DA ADMINISTRAÇÃO: QUATRO DÉCADAS DE EMPREENDEDORISMO}

Diversos fatos marcaram a trajetória e a consolidação do Curso de Administração da UNIJUÍ nestes seus 40 anos. A verticalização do ensino de Administração é uma das principais decorrências, sendo que a partir de 1990 se intensificam os Cursos de PósGraduação lato sensu em diferentes áreas: Administração Financeira, Administração Estratégica, MBA em Gestão Empresarial, Marketing, Gestão de Pessoas, Gestão da Produção, entre outros. A experiência neste nível permitiu condições para que a Administração juntamente com outros áreas das Ciências Sociais Aplicadas, iniciassem em 2002 o Programa de Pós-Graduação stricto sensu em Desenvolvimento, Gestão e Cidadania, com reconhecimento pela Capes. 
No âmbito da pesquisa, a criação do Instituto de Pesquisas e Desenvolvimento (IPD) também foi importante, contribuindo para o desenvolvimento local e regional. Relacionado a isso há participação de docentes do DACEC, tanto na gestão pública do município como na gestão da instituição, e também das empresas, mostrando que a extensão sempre foi alvo importante.

$\mathrm{Na}$ gestão municipal os professores do departamento sempre estiveram à frente de alguma secretaria municipal, ou de algum projeto relacionado ao desenvolvimento da região. Na gestão universitária, o DACEC sempre esteve e ainda está participando, na condição de vice-reitores de Administração, de Pesquisa e Extensão, e no atual momento o reitor.

A gestão de muitas empresas locais e regionais está sob o comando de egressos do Curso de Administração da Unijuí, assim com vários assumiram governos municipais.

O corpo docente do curso, devido sua qualificação, também teve um papel fundamental para o desenvolvimento do ensino superior em Administração na região, com participações em diversos outros cursos, já que o maior núcleo de professores da região se encontrava em Ijuí. Muitas vezes o curso cedeu professores para ministrarem aulas em outras cidades com o intuito de qualificar estes novos cursos como de Pós-Graduação, por exemplo.

A instituição, devido seu caráter regional, além do campus sede que se situa em Ijuí, conta com mais três campis universitários em cidades localizadas num raio de 40 a $120 \mathrm{~km}$, sendo o curso de Administração o único da universidade ofertado em todos os campi.

$\mathrm{Na}$ medida em que os professores passaram a atuar de forma mais intensa em projetos de pesquisa com as respectivas produções de trabalhos científicos, houve a necessidade de criar um periódico, no caso a Revista de Estudos de Administração (Rea), que se deu em 2000. Esta revista está classificada pelo Qualis-Capes, e possibilita a publicação de artigos em diferentes temas do campo administrativo, tendo recebido artigos de autores de diferentes universidades, o que confirma seu reconhecimento regional e nacional.

E, não se pode deixar de salientar a criação e a implementação da Empresa (Excelência) Junior, que possibilita aos estudantes uma grande experiência e também um ótimo aprendizado no contexto da realidade regional.

Os eventos realizados pela direção do Curso, junto com outras entidades parceiras favorecem a visibilidade e a qualidade do curso, como o CIDEAD (Ciclo de Debates de Administração do Rio Grande do Sul) e a Tec-e-Inova (Tecnologia e Inovação).

Atualmente, o curso conta com 34 professores (sete doutores, 24 mestres e três especialistas) mantidos pelo Departamento de Ciências Administrativas, Contábeis, 
Econômicas e da Comunicação (DACEC), e com 1187 alunos matriculados nos quatro campis (Ijuí, Santa Rosa, Panambi e Três Passos) da Universidade. Ao longo de sua história formou 1972 administradores.

\section{MEMÓRIAS DO CURSO DE ADMINISTRAÇÃO NA PERCEPÇÃO DOS DOCENTES PRECURSORES}

As memórias dos três professores que tiveram importante papel na criação do Curso de Administração, assim como os fatos mais relevantes são objeto desta parte do artigo.

A criação do curso, como menciona a professora Neyta remeteu a necessidade de pensar:

no desenvolvimento de uma nova atividade, de um novo curso, ou de uma pesquisa, se pensava dentro de um projeto maior, que era pensar na questão do desenvolvimento (...) nesse sentido é que a gente pensava, não em fazer um curso que estava na moda, mas que atendesse uma necessidade da região, e a questão do curso de Administração aparecia, logo depois da formação de professores, porque era a questão do desenvolvimento das pequenas empresas, das pequenas organizações, da Administração Pública, a qual demandava capacitação.

E para este projeto ser posto em prática era preciso de um corpo docente que atendesse o novo Curso. Assim a formação dos professores para o curso de Administração foi fruto de "um grande estímulo dado para a direção da instituição, quando a coordenadora da Fundação Ford esteve em Ijuí observando todo o trabalho que estava sendo desenvolvido de ensino superior na cidade", como bem lembra o professor Grison. Admirando o que estava sendo realizado, propôs para a direção, que eram os professores Mário Osório Marques e Argemiro Jacob Brum na época, a criação do curso. Estes dois que também tiveram significativa atuação na criação do curso, o professor Mário ao apresentar com muita propriedade e consistência a justificativa da criação do curso, seu papel nos tramites para aprovação e até no convencimento dos professores a fazerem o curso no Rio de Janeiro, e o professor Argemiro com seu grande empenho na implantação do curso, sendo seu primeiro diretor.

Depois deste estímulo e do convênio firmado com a Fundação Getúlio Vargas do Rio de Janeiro, os professores seguiram para o Sudeste do País para a capacitação em nível de Mestrado. Fato importante para a história dos quarenta anos do Curso de Administração, como também na vida pessoal e profissional dos três docentes precursores, foi este período no Rio de Janeiro, porque, como é relatado pela professora Neyta, eles não tinham

nenhuma base até então na área de Administração, eu com o curso de Sociologia, Grison e Frizzo com o curso de Filosofia, e a resposta para esta questão era a proposta da direção de não ter uma visão muito técnica do curso, e sim uma visão mais social, política e sociológica, para ter ali uma proposta bem fundamentada. 
Por esse motivo o trabalho para eles foi mais complicado do que para os demais alunos, no entanto depois de um mês os três já estavam muito bem no curso, chegando a tirar as melhores notas. O professor Frizzo explica que foi "a capacidade de estudo, a fundamentação teórica na área das Ciências Sociais e Humanas que nos facilitou”.

Muitos desafios foram enfrentados pelos professores do curso, contudo o primeiro é destacado pela professora Neyta:

pensar em um projeto político pedagógico, pensá-lo e criar condições para botá-lo em prática, em função da realidade da FIDENE, da seriedade de construir propostas de ensino engajadas na realidade, com uma preocupação pedagógica que desde o início considerasse o sujeito aluno.

Outro desafio foi o de capacitar os professores para o início e integralização do curso, uma vez que na época para ser professor, este teria de ter a aprovação do Conselho Federal de Educação. A formação de professores neste período era um pouco mais difícil, mas nada que comprometesse o processo de ensino-aprendizagem. Como existiam poucos docentes para muitas disciplinas, estes tiveram que trabalhar muitas vezes em várias delas, às vezes chegando a ministrar sete disciplinas. Um trabalho difícil, mas como recompensa tinham uma visão mais geral do curso, atingindo várias áreas de conhecimento, como destaca a professora Neyta.

No início do curso, a grande maioria dos professores das disciplinas específicas era externo à instituição, o que na época era uma dificuldade, pois as estradas nem ao menos eram asfaltadas, muitos professores por estarem dando aula já em Santa Maria não puderam dar aula em Ijuí, então se teve de buscar docentes em outros lugares. Por conta disso, o curso tinha necessidade de formar o quanto antes um núcleo de professores mais local, para superar este problema.

Em função disto, a cada ano a instituição mandava alguns bolsistas para cursos de PósGraduação lato sensu e stricto sensu como esclarece o professor Frizzo:

tão logo chegamos aqui em Ijuí, providenciamos o encaminhamento de novos bolsistas da instituição para cursos de Mestrado tanto na FGV de São Paulo como na do Rio de Janeiro, para fortalecer um corpo docente mais local.

Já no primeiro ano do curso, foram encaminhados três bolsistas para a FGV de São Paulo, voltada para Administração de Empresas. O aspecto de qualificar o quadro funcional de professores sempre foi muito importante para a instituição, que sempre investiu neste sentido. 
Outro problema eram as condições físicas da instituição como um todo, como expressa o professor Grison: "No início as condições materiais eram muito precárias, se conseguiu construir o prédio da FIDENE com doações, inclusive os próprios capuchinhos trabalhavam como pedreiros na construção do prédio". Exemplo disto eram os pisos das salas, que não possuíam nenhum tipo de revestimento sobre o chão, era concreto, porém as dificuldades neste sentido sempre foram superadas.

Neste caso até aconteceu uma história interessante e ao mesmo tempo engraçada. Como não havia revestimento no piso, a primeira turma de Administração fez um acordo com a direção da faculdade que usaria a mesma sala até o final do curso, a sala 302, então fizeram por conta própria a compra e instalação de um revestimento chamado paviflex para melhorar as condições físicas da sala. Alguns anos depois, quando os três alunos desta primeira turma se formaram (Clementino Dotti, José Alves da Silva e Roberto Christmann), a professora Neyta entregou a eles um pedaço de pavilfex que sobrou da instalação do material na época.

Os professores também lembram que uma das principais preocupações que a FIDENE tinha era a de interiorizar o ensino superior no Estado, uma vez que isso antes só existia em Santa Maria, com a UFSM. Esta questão foi muito enfatizada pelos professores, pois no início houve até certa resistência pela comunidade, pelo fato de não confiarem muito na proposta, por não terem certeza que esse campo iria dar certo, justamente por ser no interior do estado, como esclarece o professor Frizzo: "havia da parte de setores mais reacionários um preconceito, uma resistência, até uma certa aversão, de tudo que levasse o nome FIDENE”, e consequentemente essa tensão se transferia para o curso. Exemplos disso eram seminários que o curso realizava, abertos também para a comunidade, como é descrito pelo professor Frizzo:

me lembro que no primeiro semestre nós promovemos um seminário, e abrimos à
comunidade, sobre os estudos de Taylor e Fayol e havia gente que vinha de cara
torta, convidamos estas pessoas a se manifestar e elas se vangloriaram que a
empresa deles ia muito bem sem nenhum profissional do ensino superior, a empresa
faliu alguns anos depois.
Entretanto aos poucos essas tensões entre a comunidade e o curso foram se
amenizando e o curso foi ganhando confiança e respeito de todos.

Sobre a capacitação nos aspectos teóricos e questões práticas os professores salientam um ponto positivo, como o grupo de professores era pequeno, as reuniões eram frequentes, elas funcionavam como um grupo de estudo, e o que mais contribuiu para isso, com todos os professores nas entrevistas dando bastante atenção, era a boa participação de todos do grupo. O professor Grison declara que: 
estudávamos muito, fazíamos reuniões de estudo, e os professores não eram muitos, se tinha muita convivência, fazíamos jantas e almoços, se discutia os temas, as preocupações, com o desenvolvimento da região, um clima de muita participação de todos.

Outros desafios lembrados pelos docentes foram os estágios supervisionados, "os professores não tinham a sistemática estruturada, então se esperava que o próprio aluno produzisse seu estágio", o que era uma grande dificuldade para eles.

Todas essas dificuldades enfrentadas pelos docentes precursores do curso, algumas consequentemente também para os alunos e direção foram geradas em função de um pioneirismo, uma interiorização, de um campo até então desconhecido e questionado na região noroeste do Rio Grande do Sul, aspecto sempre muito enfatizado pelos professores durante as entrevistas.

Segundo os professores pode-se dizer hoje, que as expectativas do curso foram alcançadas, pois a instituição, hoje como Universidade possuí um grande núcleo de professores qualificados e enraizados na cidade, chegando até a exportar docentes para todo o país, como explica a professora Neyta: “já estamos na terceira geração de professores formados por nós mesmos".

Outra expectativa na criação do curso era criar novos cursos na mesma área, como Faculdade de Ciências Administrativas, Contábeis e Econômicas de Ijuí (FACACEI) era natural que os professores tinham a intenção de criar os cursos de Economia e Ciências Contábeis, porém os docentes sempre tentaram de alguma forma não atropelar os passos, para não ter um trabalho de má qualidade desenvolvido. E, alguns anos depois foram criados os cursos de Ciências Contábeis (1975) e Economia (1989).

Os alunos também sempre fizeram parte das expectativas dos professores, sempre dando muita ênfase ao sujeito aluno, sempre trabalhando de diversas maneiras de capacitar estes para crescerem em seu campo de compreensão na realidade em questão. E para isso acontecer, a professora Neyta se lembra das práticas pedagógicas alternativas:

usamos dinâmicas que favorecessem o trabalho criativo para seus estudos e apresentações em linguagens diversas como: o desenho, o teatro, a música, a modelagem, entre outras ferramentas para socializar suas descobertas nos trabalhos do semestre com temas determinados a partir dos eixos propostos para cada semestre.

Neste sentido, a intenção era a valorização do processo de construção do conhecimento, o que exigiu muito acompanhamento dos professores com seus alunos, ajudando os mesmos até fora dos horários das aulas. 
Portanto, todas essas memórias retratam um caminho de muitos desafios e adversidades enfrentados pelos professores. Contudo, ao considerar a trajetória bem sucedida, pode-se afirmar que todo o trabalho desenvolvido é recompensador, tanto para aqueles que se dedicaram intensamente a este projeto, como para aqueles que se beneficiaram e ainda vem se beneficiando com o Curso de Administração da UNIJUÍ. Esta graduação é marcada por seu empreendedorismo e, sobretudo pioneirismo no interior do Estado do Rio Grande do Sul.

\section{CONSIDERAÇÕES FINAIS}

A pesquisa buscou trazer a história dos 40 anos do curso de Administração na UNIJUÍ a partir da percepção dos docentes bandeirantes, que foram os principais sujeitos na criação do curso, tanto na solução dos problemas, quanto na capacitação destes no nível de Mestrado.

$\mathrm{O}$ estudo permitiu o entendimento de vários aspectos relacionados ao pioneirismo que o curso de Administração trouxe para a região noroeste do estado do RS, assim como os desafios enfrentados pelos professores, seus problemas no contexto regional, suas expectativas com relação ao curso, principais fatos marcantes nestas quatro décadas, e as perspectivas futuras.

O levantamento histórico evidenciou o importante papel que os primeiros professores tiveram para o êxito do um projeto inovador e empreendedor no ensino superior de Administração, com uma trajetória de quarenta anos, confirmando o slogan do curso "Seus frutos projetam o futuro", não só de Ijuí, como também do RS e do Brasil.

Por fim, espera-se com este trabalho incentivar outros estudos sobre a memória das instituições, sobretudo de instituições de ensino superior, um campo ainda pouco explorado por pesquisadores, e que é interessante pela possibilidade de resgatar e sistematizar uma história desconhecida por pessoas que trabalham até dentro desta mesma instituição. A memória organizacional deve se constituir, portanto, num processo sistemático e contínuo, integrando conhecimento, aprendizagem e competências no âmbito das organizações contemporâneas.

\section{REFERÊNCIAS}

ANDRADE, R. O. B. de; AMBONI, N. Projeto pedagógico para cursos de Administração. São Paulo: Makron Books, 2002. 
BARBOSA, M. A. G.; OTT, E. Uma Contribuição à Historiografia do Ensino Contábil no Estado do Rio Grande do Sul. XXXIII EnANPAD 2009. São Paulo/SP. ANAIS... São Paulo, 2009.

BORENSTEIN, M. S.; ALTHOFF, C. R.; SOUZA, M. de L. de; Enfermagem da UFSC: Recortes de Caminhos Construídos e Memórias. Florianópolis: Insular, 1999.

COIMBRA, C. J. O Sistema CFA/CRAs no Contexto da Administração no Brasil. São Paulo: Via Impressa Edições de Arte, 2010.

CURADO, I. Pesquisa Historiográfica em Administração: uma proposta metodológica. XXV EnANPAD 2001. Campinas/SP. ANAIS... Rio de Janeiro, 2001.

Fundação de Integração, Desenvolvimento e Educação do Noroeste do Estado. Relatório Trianual 1972 a 1974. (1975) Arquivo: MADP.

Fundação de Integração, Desenvolvimento e Educação do Noroeste do Estado. Relatório Trianual 1969 a 1971. (1972) Arquivo: MADP.

Fundação de Integração, Desenvolvimento e Educação do Noroeste do Estado. Balanço e Relatório anual de 1971. (1972) Arquivo: MADP.

Fundação de Integração, Desenvolvimento e Educação do Noroeste do Estado. Relatório do processo de autorização para funcionamento do Curso de Administração. (1970) Arquivo: MADP.

FISCHER, T. A perduração de um mestre e uma agenda de pesquisas na educação de Administração: artesanato de si, memória dos outros e legados de ensino. Revista Organizações \& Sociedade, Salvador, v. 17, n.52, jan./mar. 2010, p. 209-219.

FISCHER, T.; SILVA, M. R. Ensino de Administração: Um Estudo da Trajetória Curricular de Cursos de Graduação. XXXIV EnANPAD, 2010. Rio de Janeiro/RJ. ANAIS... Rio de Janeiro, 2010.

FLEURY, M. T. L. Aprendizagem e gestão do conhecimento. In. DUTRA, Joel Souza (Org). Gestão por competências: um modelo avançado para o gerenciamento de pessoas. São Paulo: Gente, 2001.

FLEURY, M. T. L.; OLIVEIRA JR, M. M. Gestão estratégica do conhecimento: integrando aprendizagem, conhecimento e competências. São Paulo: Atlas, 2001.

MARQUES, T. C. de N. História de Empresas, Memórias e Fontes. XIX EnANGRAD. Anais... Curitiba, 2008.

MEC. Disponível em: http://emec.mec.gov.br/. Acesso em: 23/04/2011.

MINAYO, M. C. de S. (Org). Pesquisa social: teoria, método e criatividade. Rio de Janeiro: Vozes, 1994. 
NONAKA, I. A empresa criadora de conhecimento. In. Gestão do conhecimento. Harvard Business Review. Rio de Janeiro: Campus, 2000.

NONAKA, I.; TAKEUCHI, H.. Criação de conhecimento na empresa: como as empresas japonesas geram a dinâmica da inovação. Rio de Janeiro: Campus, 1997.

SARAIVA, L. A. S.; COSTA, A. M. da. O que lembrar e o que esquecer? Memória e a Formalização Social do passado nas organizações. XXXIV EnANPAD 2010. Rio de Janeiro/RJ. ANAIS... Rio de Janeiro, 2010.

SPENDER, J. C. Gerenciando sistemas de conhecimento. In. FLEURY, Maria Tereza Leme; OLIVEIRA JR, Moacir Miranda. Gestão estratégica do conhecimento: integrando aprendizagem, conhecimento e competências. São Paulo: Atlas, 2001.

VERGARA, S. C. Métodos de coleta de dados no campo. São Paulo: Atlas, 2009.

VERGARA, S. C. Métodos de pesquisa em administração, São Paulo: Atlas, 2005.

WAINANDT, C.; FISCHER, T. M. D.; FONSECA, R. L. A História do Ensino em Administração: Contribuições Metodológicas e uma Proposta de Agenda de Pesquisa. XXXIV EnANPAD, 2010. Rio de Janeiro/RJ. ANAIS... Rio de Janeiro, 2010.

YIN, R. K. Estudo de caso - planejamento e métodos. 2. Ed. Porto Alegre: Bookman, 2001. 